\title{
IMPLICATIONS OF THE TIME REQUIRED FOR MINIMUM AND TERTIARY CREEP RATES FOR ICE MINING AND TUNNEL CLOSURE
}

\author{
(Abstract only)
}

\author{
by \\ T. H. Jacka \\ (Antarctic Division, Kingston, Tasmania 7150, Australia) \\ and W. F. Budd
}

(Meteorology Department, University of Melbourne, Parkville, Victoria 3052, Australia)

\section{ABSTRACT}

For the calculation of rates of closure of tunnels or bore holes in ice, the use of a flow law relation based on secondary or minimum creep rates necessarily underestimates closure rates, particularly for large strains where much higher tertiary creep rates develop. Long-term laboratory studies have shown that the change in strain-rate from primary to secondary or minimum and to an approximately constant tertiary stage is associated with recrystallization and the development of strong crystal-orientation fabrics which are dependent on the stress configuration, but not appreciably on crystal size. For bore holes, tunnels or cavities constructed in ice, initial rates of closure decrease, in primary creep, to a minimum value (at about $1 \%$ strain) dependent on stress and temperature. From this time, increasing strain-rates occur, analogous to the results obtained from the laboratory studies. A 25-year record of closure of a tunnel at about 30 m depth at site S2 on Law Dome, Antarctica, illustrates the application of the laboratory-derived relations. Comparison between the results of deformation from bore holes, tunnels and laboratory tests, comprising various stress configurations, under similar conditions of stress and temperature, indicates that the strain-rates are compatible when considered as a function of total strain. 